\title{
Comparison of spontaneous ascites filtration and reinfusion with total paracentesis with intravenous albumin infusion in cirrhotic patients with tense ascites
}

\author{
S Bruno, M Borzio, M Romagnoni, P M Battezzati, S Rossi, A Chiesa, M Podda
}

Abstract

Objective-To compare the effectiveness and safety of spontaneous ascites filtration and reinfusion and total paracentesis plus intravenous albumin infusion in cirrhotic patients with tense ascites.

Design-Randomised trial of the two treatments.

Setting-Teaching hospital and district general hospital in Milan.

Patients -45 consecutive cirrhotic patients with recurrent tense ascites and urinary sodium excretion rate $<\mathbf{2 0} \mathbf{m m o l} /$ day. 35 fulfilled admission criteria and completed the study. 17 received spontaneous ascites filtration and $\mathbf{1 8}$ paracentesis plus albumin infusion.

Main outcome measures-Body weight; urinary volume; serum and urinary electrolyte, serum fibrinogen, and plasma aldosterone concentrations; and plasma renin activity before the procedure and 24 hours and eight days afterwards.

Results-Both procedures were effective in all patients. Weight decreased in both groups and showed no substantial increase after eight days. In patients receiving ascites filtration, values decreased significantly $(p<0.01)$ after 24 hours for platelet count (mean relative change $0.92 ; 99 \%$ confidence interval 0.86 to 0.98 ) and serum fibrinogen concentration $(0.92 ; 0.88$ to 0.98$)$ but returned to pretreatment values after eight days; no laboratory and clinical signs of disseminated intravascular coagulation were noted. Three patients in this group had fever, which receded spontaneously. One patient in each group had dilutional hyponatraemia.

Conclusions-Spontaneous ascites filtration and reinfusion is an effective treatment for tense ascites. Reinfusion of the patient's concentrated proteins provides savings without compromising safety.

Medicine, St Paolo

Hospital Medical School,

University of Milan, Milan,

Italy

S Bruno, assistant

P M Battezzati, assistant

S Rossi, assistant

A Chiesa, assistant

$M$ Podda, professor of

medicine

First Department of Medicine and Nephrology

Unit, Fatebenefratelli

Hospital, Milan

M Borzio, assistant

M Romagnoni, assistant

Correspondence to: $\operatorname{Dr} S$ Bruno, Department of Internal Medicine, Istituto Scienze Biomediche S Paolo, 20142 Milano, Italy. and cost of spontaneous ascites filtration and reinfusion in cirrhotic patients with tense ascites.

\section{Patients and methods}

All patients consecutively admitted to our two hospitals for treatment of an episode of tense ascites between January 1988 and February 1989 were considered for admission into the study. Criteria for inclusion were liver cirrhosis with tense ascites and urinary sodium excretion rate lower than $20 \mathrm{mmol} /$ day serum bilirubin concentration $<85 \mu \mathrm{mol} / \mathrm{l}$; serum creatinine concentration $<265 \mu \mathrm{mol} / 1$; prothrombin time $<18 \mathrm{~s}$; platelet count $>50 \times 10^{9} / 1$. Criteria for exclusion were clinical, laboratory, or ultrasonographic data suggesting hepatocellular carcinoma; presence of severe hepatic encephalopathy (stage III and IV); gastrointestinal haemorrhage or infection during the previous month; spontaneous bacterial peritonitis, as defined by the criteria of Runyon $e^{2} a^{8}$; treatment with non-steroidal anti-inflammatory drugs during the previous month.

On the first day of admission to hospital diuretic treatment was discontinued and the patients were put on a low sodium diet $(20 \mathrm{mmol} / \mathrm{day})$, with fluid intake restricted to $500 \mathrm{ml} /$ day in patients with serum sodium levels $<130 \mathrm{mmol} / \mathrm{l}$ and to $11 /$ day in the remaining patients. On the morning after the third day of this regimen, after an overnight fast, the following were measured to assess eligibility and to obtain baseline evaluations: blood urea nitrogen, serum creatinine, and plasma electrolyte (also measured in 24 hour urine samples) concentrations; liver function tests; concentrations of fibrinogen and fibrin degradation products; plasma renin activity; and plasma aldosterone concentration. White cell count and total protein and albumin concentration in the ascitic fluid were also determined. Thirty five out of 45 patients fulfilled the criteria for inclusion; 10 patients were excluded because of: serum bilirubin concentration $>85 \mu \mathrm{mol} / \mathrm{l} \quad(\mathrm{n}=1)$, urinary sodium excretion $>20 \mathrm{mmol} / \mathrm{day} \quad(n=4)$, serum creatinine concentration $>265 \mathrm{mmol} / \mathrm{l}(\mathrm{n}=1)$, prothrombin time $>18 \mathrm{~s}(\mathrm{n}=1)$, platelet count $<50 \times 10^{9} / 1$ $(n=1)$, hepatocellular carcinoma $(n=2)$. After assessment for eligibility, and on the morning of the procedure, patients were randomly assigned by the sealed envelope method on the basis of a computer generated list to either spontaneous ascites filtration and reinfusion or to total paracentesis plus intravenous albumin infusion.

Spontaneous ascites filtration and reinfusion was performed as described by Landini et al. ${ }^{7}$ In detail, patients lie in bed at least $1 \mathrm{~m}$ above the floor. After needle puncture of the peritoneal cavity a 14 gauge catheter is inserted into the left lower abdominal quadrant and connected to a prepackaged sterile set, including a drainage bag for collection of the filtrate 
and another bag for collection of concentrated ascites. For ascites filtration and concentration, a polyamide fibre haemofilter (FH 88, Gambro, Lund, Sweden) with an effective surface area of $2 \mathrm{~m}^{2}$ was used. The ascitic fluid flows through the filter, gravity providing the transmembrane pressure necessary for separation of proteins from water and solutes (fig $1 a$ ). Progressive protein concentration is obtained by successive passages of the partially concentrated proteins back into the abdominal cavity and again into the protein bag while the filtrate is drained out. This is accomplished simply by repeatedly moving the protein bag above and below the haemofilter (fig $1 b$ ). Thus, the abdominal cavity serves as a mixing chamber for a progressively concentrated ascitic fluid, which is alternately withdrawn from and delivered back to the peritoneum. The concentrate obtained after the last passage is then

a

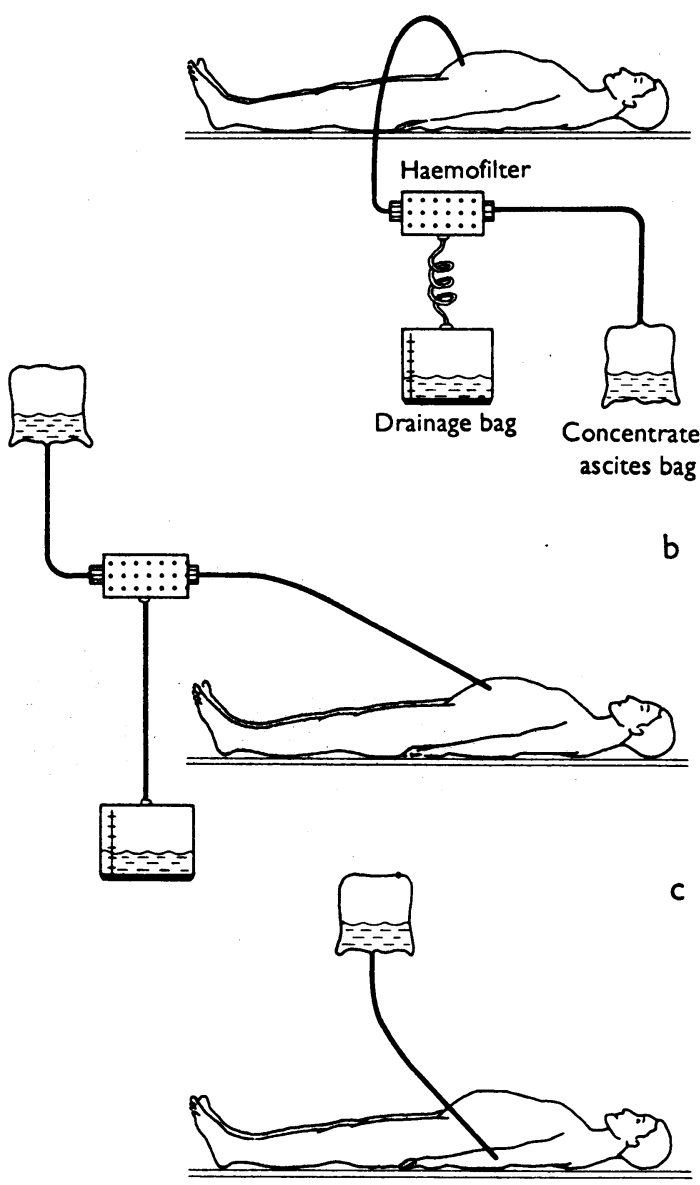

FIG 1-Procedure for spontaneous ascites filtration and reinfusion. Ascitic fluid is passed repeatedly through the abdominal cavity by moving bag above and below haemofilter. Concentrate is reinfused through a catheter

TABLE I-Characteristics of cirrhotic patients treated for tense ascites. Data are geometric means (95\% confidence intervals) unless stated otherwise

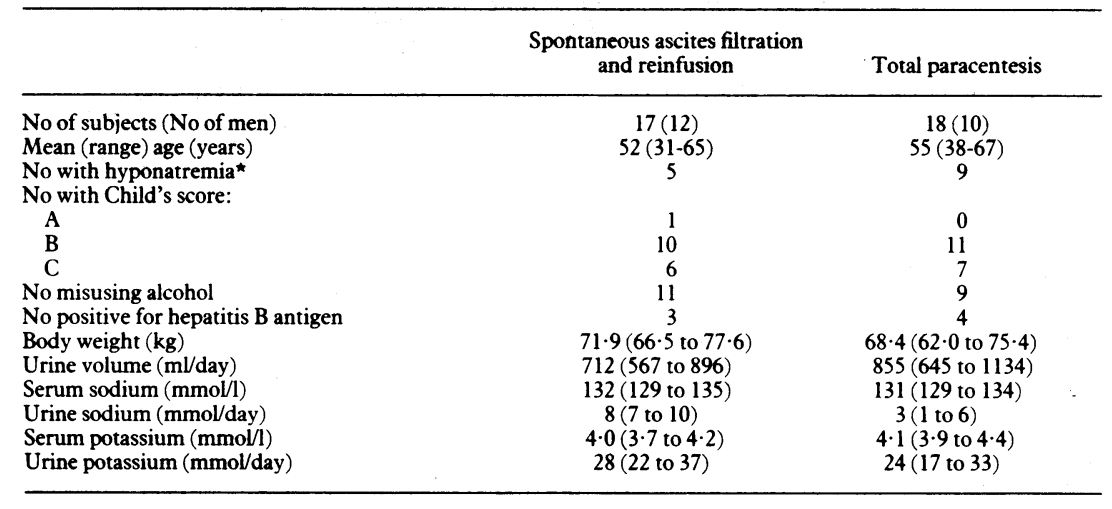

$\star$ Serum sodium concentration $<130 \mathrm{mmol} / \mathrm{l}$ reinfused through a catheter inserted into an antecubital vein (fig $1 c$ ).

Patients in the total paracentesis group had a single step procedure, as described by Titò et al. ${ }^{2}$ After paracentesis patients remained in bed, resting on the opposite side to prevent leakage, and intravenous albumin infusion (4-6 g for each liter of ascites removed) was started. The study has been carried out according to the principles of the Helsinki declaration for research in human subjects. All patients gave their informed consent.

\section{EVALUATION OF TREATMENTS}

For both groups heart rate; blood pressure; serum creatinine, blood urea, and serum sodium and potassium concentrations; urinary sodium and potassium excretion; plasma renin activity; and plasma aldosterone concentration were determined at entry, and 24 hours and eight days after the procedure. For patients treated with spontaneous ascites filtration and reinfusion prothrombin time, partial thromboplastin time, and concentrations of fibrinogen and fibrin degradation products were also determined at the same time.

Baseline determinations were repeated on the eighth day after treatment to assess the efficacy of both procedures. Treatment failure was predefined as an increase in body weight of more than $50 \%$ of the weight loss after paracentesis.

ANALYSIS OF DATA

Natural logarithms (ln) were applied to the variables under study to minimise correlations between the mean and the variance of the data and departures from normality. To avoid values close to zero $\ln (x+1)$ was calculated for each variable. Their means, standard errors, and confidence intervals were calculated as logarithmic values and then transformed back into the original scale to be reported in the text.

Data were analysed by mixed factorial analysis of variance. The adjusted Huynh-Feld probabilities were used for significance testing after examination of the sphericity test. ${ }^{9}$ If tests for changes over time or related interactions, or both, attained significance $(p<0.05)$ the mean values at the various times were compared within each treatment group by the Student-NewmanKeuls test. ${ }^{10}$

Changes in each of the variables over the period of study were reported as geometric mean relative changes (the difference between values recorded at each time and initial values in the logarithmic scale, which in the original scale corresponds to the ratio of values at each time to initial values) and their confidence intervals. Two tailed $p$ values were used for statistical comparisons.

\section{Results}

Table I shows the characteristics of the patients studied.

Both procedures resulted in improvement of the subjective symptoms in all patients. No patients dropped out from the study. The mean time needed to perform the procedures was 5 (range 2 to 10 ) hours for spontaneous ascites filtration and reinfusion and 2 ( 1 to 3.5) hours for total paracentesis plus intravenous albumin infusion. Operator intervention was required only intermittently - that is, at the beginning and end of each procedure and, for spontaneous ascites filtration and reinfusion, about five to eight times (1-2 minutes each) during the procedure-for an overall period of 20-30 minutes. The volume of ascites removed was similar for the spontaneous ascites filtration and reinfusion group (7.0 (3.5-11.0) 1$)$ and for the total paracentesis group $(6 \cdot 4(4 \cdot 0-10 \cdot 0)$ 1). In patients 
TABLE II-Geometric means (95\% confidence intervals) for clinical and laboratory variables in patients treated with spontaneous ascites filtration and reinfusion (group $A$ ) and total paracentesis (group $B$ )

\begin{tabular}{|c|c|c|c|}
\hline & \multirow[b]{2}{*}{ Baseline } & \multicolumn{2}{|c|}{ Change from baseline ${ }^{\star}$} \\
\hline & & Day 1 & Day 8 \\
\hline \multicolumn{4}{|c|}{ Heart rate (beats $/ \mathrm{min}$ ): } \\
\hline Group A & $79(73$ to 84$)$ & $1.04(1.01$ to 1.08$)$ & $1.02(0.99$ to 1.05$)$ \\
\hline Group B & $76(69$ to 83$)$ & $1.03(0.97$ to 1.09$)$ & $1.02(0.95$ to 1.10$)$ \\
\hline \multicolumn{4}{|c|}{ Mean arterial pressure $(\mathrm{mm} \mathrm{Hg})$ : } \\
\hline Group A & 89 (84 to 95$)$ & $1.01(0.96$ to 1.05$)$ & $0.99(0.94$ to 1.05$)$ \\
\hline Group B & $88(83$ to 93$)$ & $0.97(0.94$ to 1.00$)$ & $1.01(0.97$ to 1.05$)$ \\
\hline \multicolumn{4}{|c|}{ Urine potassium $(\mathrm{mmol} / \mathrm{day})$ : } \\
\hline Group A & 28 ( 22 to 37$)$ & $1.16(0.83$ to 1.62$)$ & $1.04(0.70$ to 1.53$)$ \\
\hline Group B & 24 (17 to 33 ) & $1.08(0.93$ to 1.26$)$ & $1 \cdot 17(0.90$ to 1.54$)$ \\
\hline \multicolumn{4}{|c|}{ Serum sodium $(\mathrm{mmol} / \mathrm{l})$ : } \\
\hline Group A & $132(129$ to 135$)$ & $1.00(0.99$ to 1.01$)$ & $1.00(0.98$ to 1.01$)$ \\
\hline Group B & $131(129$ to 134$)$ & $1.01(0.98$ to 1.03$)$ & $1.01(0.99$ to 1.03$)$ \\
\hline \multicolumn{4}{|c|}{ Blood urea $(\mathrm{mmol} / \mathrm{l})$ : } \\
\hline Group A & $8.6(6.8$ to 11.8$)$ & $1.11(0.98$ to 1.27$)$ & $1.27(1.04$ to 1.55$)$ \\
\hline Group B & $11 \cdot 1(7 \cdot 8$ to $15 \cdot 4)$ & $1.07(0.97$ to 1.19$)$ & $1.17(1.00$ to 1.37$)$ \\
\hline \multicolumn{4}{|c|}{ Serum creatinine $(\mathrm{mmol} / \mathrm{l})$ : } \\
\hline Group A & $79 \cdot 6(61 \cdot 9$ to $97 \cdot 2)$ & $0.97(0.91$ to 1.03$)$ & $0.98(0.92$ to 1.04$)$ \\
\hline Group B & $88 \cdot 4(70 \cdot 7$ to $106 \cdot 1)$ & $0.99(0.97$ to 1.01$)$ & $1.00(0.96$ to 1.04$)$ \\
\hline
\end{tabular}

^The changes between values at entry and those at 1 and 8 days after each procedure are expressed as a ratio. Values greater than 1 indicate increase from baseline; those equal to or less than 1 indicate no change or decrease from baseline.

treated with spontaneous ascites filtration and reinfusion both albumin content of the ultrafiltrate and albumin remaining in the filter at the end of the manoeuvre were negligible. The mean amount of commercially available albumin reinfused into patients in the total paracentesis group was $42(19-66) \mathrm{g}$.

Table II shows the changes in the most relevant clinical variables after one and eight days and figure 2 shows those changes that were significant. In the spontaneous ascites filtration and reinfusion group there were significant decreases $(p<0 \cdot 01)$ from baseline values in platelet count (mean relative change 0.92 ; $99 \%$ confidence interval 0.86 to 0.98 ) and serum fibrinogen concentration $(0.92 ; 0.88$ to 0.98$)$ after 24 hours. Both of these returned to baseline values by the
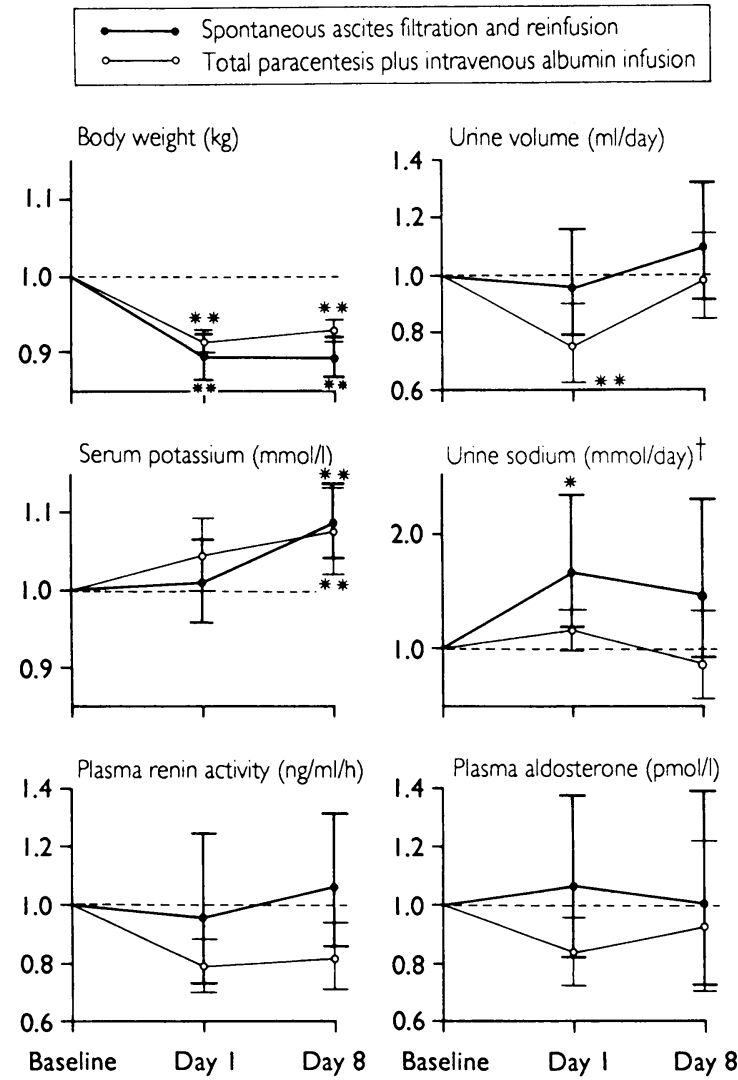

FIG 2-Geometric mean relative changes from baseline for clinical and laboratory variables after spontaneous ascites filtration and reinfusion and total paracentesis plus albumin infusion. Bars indicate $95 \%$ confidence intervals of such changes. Values higher than 1.0 indicate increase from baseline, those equal or less than $1 \cdot 0$ indicate no change or decrease from baseline. ${ }^{\star} p<0.05,{ }^{\star \star} p<0.01$ for change from baseline; $t p<0.01$ for difference between groups eighth day. Soon after the reinfusion of the concentrate two patients treated with spontaneous ascites filtration and reinfusion developed mild and transient fever, which did not require treatment. Dilutional hyponatraemia occurred in one patient from each group. One patient in the total paracentesis group, who had tolerated the treatment well, died of liver failure while in hospital 10 days after the procedure was performed.

\section{Discussion}

Three controlled trials have so far shown that large volume paracentesis plus intravenous albumin infusion is a safe and effective treatment for tense ascites in patients with cirrhosis. Other procedures that would enable removal of a large volume of ascitic fluid while avoiding the use of commerical albumin would be useful because the high cost of human albumin does not allow its routine use under the national health services of most countries. Our study provides evidence that spontaneous ascites filtration and reinfusion, a simple technique for concentration and reinfusion of ascitic fluid, is as effective as total paracentesis plus intravenous albumin infusion for treating tense ascites.

After both procedures body weight did not increase significantly from initial values despite the discontinuation of diuretic treatment in all patients throughout the observation period. No patient developed kidney impairment or severe hyponatraemia. These data confirm our previous results ${ }^{3}$ and those of other groups, ${ }^{56}$ indicating that the infusion of albumin without diuretic treatment can prevent rapid reaccumulation of ascitic fluid after paracentesis.

In the past two decades several procedures for ascites concentration and recirculation have been proposed to treat refractory ascites, the most popular being the Rhodiascit apparatus. ${ }^{11-14}$ However, the Rhodiascit procedure has important drawbacks. It can induce cardiovascular and coagulation problems, and several hours are required to remove and concentrate the ascites. The high permeability of the haemofilter used in our study provides rapid and effective concentration of ascitic fluid and a small amount of protein rich concentrate for reinfusion. The membrane characteristics might also explain the absence in our study of the major coagulation disorders that were reported with the Rhodiascit apparatus. The transient decrease in platelet counts that we observed in the spontaneous ascites filtration and reinfusion group was small and not clinically relevant. In the same group there were two episodes of fever, which were self limiting and did not require treatment. We carefully excluded infection of ascitic fluid at baseline or in the recent history of patients. Fever may be due to the reinfusion of concentrated proteins into the blood because it is well established that ascitic fluid often contains pyrogenic substances. ${ }^{1516}$

\section{COST EFFECTIVENESS}

The probability of readmission to the hospital for reaccumulation of ascitic fluid has been shown to be high for patients treated with paracentesis and subsequent diuretic administration. For these patients spontaneous ascites filtration and reinfusion is less expensive than total paracentesis plus intravenous albumin infusion. We have calculated that the average cost per 10 litres of ascites removed is about $\$ 360$ for total paracentesis plus intravenous albumin infusion, but about $\$ 156$ for spontaneous ascites filtration and reinfusion. Furthermore, the haemodialysis filter could be reused for the same patient, with an additional saving. Medical intervention is required only at the beginning and end of the procedure, as with the 
conventional procedure, while nursing intervention is limited to periodic lifting of the bag containing concentrated proteins. In our experience this technique requires only minimal training of junior doctors and nurses, and it can be safely performed without supervision after being carried out three or four times. Moreover, this part of the procedure can now be automated by using a new dedicated machine (Bellco, Mirandola, Italy).

The use of less expensive albumin substitutes has also been recently suggested..$^{17}$ Polygeline was recently shown to be a safe replacement for human albumin for re-expanding plasma volume in cirrhotic patients with refractory ascites ${ }^{18}$ However, the efficacy and safety of long term use of these compounds in patients with relapsing ascites is still unknown. Planas et al showed that dextran 70 significantly increased plasma renin activity and plasma aldosterone concentrations in patients who had total paracentesis. ${ }^{17}$ Their data suggest that dextran 70 is less effective than albumin in protecting patients from a decrease in intravascular volume.

In conclusion, our study indicates that short term treatment with spontaneous ascites filtration and reinfusion is safe and effective and that it is less expensive than total paracentesis plus intravenous albumin infusion for treating tense ascites. Further studies aimed at comparing the efficacy and safety of long term treatment with spontaneous ascites filtration and reinfusion with total paracentesis plus albumin or polygeline infusion in cirrhotic patients with recurrent ascites are warranted.

We thank Dr M L Petroni for her advice and useful criticism in revising the paper as well as for continued support and encouragement.
1 Ginès P, Arroyo V, Quintero E, Planas R, Cabrera J, Bory F, et al. Comparison of paracentesis and diuretics in the treatment of cirrhotics with tense ascites. of paracentesis and diuretics in the treatment of cirrhotics with tense

2 Titò L, Ginés P, Arroyo V, Planas R. Total paracentesis associated with Titò $\mathrm{L}$, Ginés $\mathrm{P}$, Arroyo $\mathrm{V}$, Planas $\mathrm{R}$. Total paracentesis associated with
intravenous albumin in the management of patients with cirrhosis and intravenous albumin in the manageme
ascites. Gastroenterology 1990;98:146-51.

3 Salerno F, Badalamenti S, Incerti P, Tempini S, Restelli B, Bruno S, et al. Repeated paracentesis and i.v. albumin infusion to treat 'tense' ascites in cirrhotic patients. A safe alternative therapy. $\mathcal{F}$ Hepatol 1987;5:102-8.

4 Schiff ER. Paracentesis: a safe and effective form of therapy. Hepatology 1987;7:591-2.

5 Ginés P, Titò L, Arroyo V, Planas R, Panes J, Viver J, et al. Randomized comparative study of therapeutic paracentesis with and without intravenous albumin in cirrhosis. Gastroenterology 1988;94:1493-502.

6 Simon DM, McCain JR, Bonkovsky HL, Wells JO, Hartle DK, Galambos JT, et al. Effect of therapeutic paracentesis on systemic and hepatic hemodynamics and on renal and hormonal function. Hepatology 1987;7:423-9.

7 Landini S, Coli U, Fracasso A, Morachiello P, Righetto F, Scanferla F, et al. Spontaneous ascites filtration and reinfusion (SAFR) in cirrhotic patients. Spontaneous ascites filtration and
Int $\mathcal{F}$ Artif Organs 1985;8:227-80.

8 Runyon BA, Canawati HN, Akriviadis EA. Optimization of ascitic fluid culture technique. Gastroenterology 1988;95:1351-5.
culim

9 Huynh H, Feld LS. Estimation of the Box correction for degrees of freedom from sample data in the randomized block and split-plot designs. Fournal of Educational Statistics 1976;1:69-82.

10 Winer BJ. Statistical principles in experimental design. 2nd ed. New York: McGraw-Hill, 1971:518-39.

11 Tawes RL, Rydorak GR, Kennedy PA. Coagulation disorder associated with peritoneovenous shunting. Am $\mathcal{F}$ Surg 1981;142:51-5.

12 Wilkinson SP, Henderson J, Davidson AR. Ascites reinfusion using the Rhodiascit apparatus -clinical experience and coagulation abnormalities. Postgrad Med f 1975;51:583-7.

13 Smart HL, Triger DR. A randomized prospective trial comparing daily paracentesis and intravenous albumin with recirculation in diuretic refractory ascites. F Hepatol 1990;10:191-7.

14 Wilde JT, Cooper P, Kennedy HJ, Triger DR, Preston FE. Coagulation disturbances following ascites recirculation. $\mathcal{F}$ Hepatol 1990;10:217-22.

15 Ansley JD, Bethel RA, Bower PA, Warren WD. Effect of peritonevenous shunting with Le Veen valve on ascites, renal function and coagulation in six shunting with Le Veen valve on ascites, renal function and

16 Mortenson RA, Lawton RL. Surgery treatment for intractable ascites. Am $\mathcal{f}$ Surg 1968;116:929-32.

17 Planas R, Ginés P, Arroyo V, Llach J, Panes J, Vargas V, et al. Dextran-70 versus albumin as plasma expanders in cirrhotic patients with tense ascites
vet treated with total paracentesis. Results of a randomized study. Gastroenterology 1990;99:1736-44.

18 Salerno F, Badalamenti S, Lorenzano E, Moser P, Incerti PL. Randomized comparative study of hemaccel vs albumin infusion after total paracentesis in cirrhotic patients with refractory ascites. Hepatology 1991;13:707-13.
Western Australian

Research Institute for Child Health, Princess Margaret Hospital for Children, GPO Box D184, Perth, Western Australia 6001 Fiona J Stanley, director Linda Watson, research clerk

Correspondence to: Professor Stanley.

BMf 1992;304:1658-63

\section{Trends in perinatal mortality and cerebral palsy in Western Australia, 1967 to 1985}

\author{
Fiona J Stanley, Linda Watson
}

\begin{abstract}
Objective-To analyse the trends in stillbirths, neonatal deaths, and cerebral palsy in all infants born in Western Australia from 1967 to 1985. To relate these trends to changes in perinatal care, particularly in relation to avoidance of intrapartum asphyxia in term infants and the increased survival of low birthweight infants.

Design-Descriptive epidemiological study calculating population rates for perinatal deaths and cerebral palsy according to year of birth and birth weight.

Setting-Western Australia.

Subjects-All infants born after 20 weeks' gestation or weighing at least $\mathbf{4 0 0} \mathrm{g}$ (live and stillborn).

Main Outcome Measures-Stillbirths, neonatal deaths (from perinatal death certificates), and cerebral palsy (from a population based register).

Results-Overall stillbirth rates fell from $12 \cdot 1$ / 1000 total births in $1967-70$ to $8 \cdot 1$ in $1983-5$. Early neonatal mortality fell from $13 \cdot 0 / 1000$ live births to 4.4 over the same period whereas total cerebral palsy rates remained at around $2 \cdot 2 \cdot 5 / 1000$ live births. Death rates fell in all birth weight categories, particularly in low birthweight infants between 1975 and 1985, the period when birthweight data were available. In contrast, cerebral palsy rates in infants under $1500 \mathrm{~g}$ rose significantly over this period (from
\end{abstract}

$12 \cdot 1$ in 1968 to 64.9 in 1985). The rise was seen in all spastic categories, including severely and multiply handicapped children.

Conclusions - Large increases in the use of interventions aimed at reducing birth asphyxia and handicaps had not (by 1985) resulted in lower rates of cerebral palsy. This suggests that birth asphyxia is not a major cause. The increased survival of low birthweight infants has resulted in more cerebral palsy in this group, due either to postnatal complications of immaturity or prenatal damage to the fetal brain. These findings have implications for planning perinatal care and for litigation for putative obstetric malpractice in cerebral palsy cases.

\section{Introduction}

As the proportions of stillbirths and neonatal deaths have fallen in most developed countries interest has increased in using the trends of occurrence of cerebral palsy as a measure of the benefits and hazards of obstetric (intrapartum) and neonatal care. Most countries record deaths as part of their vital registration, but few have population data on cerebral palsy, which require special collection.'

There is also concern about the increasing expensive litigation in the United States, ${ }^{2}$ United Kingdom, ${ }^{3}$ and now Australia ${ }^{45}$ for children born with cerebral palsy, 